\title{
Pitfalls of the most commonly used models of context dependent
} substitution

\author{
Helen Lindsay ${ }^{1}$, Von Bing Yap², Hua Ying ${ }^{1}$ and Gavin A Huttley*1
}

Address: ${ }^{1}$ Computational Genomics Laboratory, John Curtin School of Medical Research, The Australian National University, Canberra, ACT 0200, Australia and 2Department of Statistics and Applied Probability, National University of Singapore, Kent Ridge, Singapore

Email: Helen Lindsay - Helen.Lindsay@anu.edu.au; Von Bing Yap - stayapvb@nus.edu.sg; Hua Ying - hua.ying@anu.edu.au; Gavin A Huttley* - gavin.huttley@anu.edu.au

* Corresponding author

Published: 18 March 2009

Biology Direct 2009, 4:10 doi:10.1186/1745-6150-4-10
Received: 6 March 2009

Accepted: 18 March 2009

This article is available from: http://www.biology-direct.com/content/4/I/10

(C) 2009 Lindsay et al; licensee BioMed Central Ltd.

This is an Open Access article distributed under the terms of the Creative Commons Attribution License (http://creativecommons.org/licenses/by/2.0), which permits unrestricted use, distribution, and reproduction in any medium, provided the original work is properly cited.

\section{Correction}

The published version of this article [1] includes a link to the incorrect version of 'Additional File Two'. The correct version of the file is included here as Additional file 1.

\section{Additional material}

\section{Additional file 1}

Scripts used in the study. Archive of stand-alone web site presenting the central scripts used in this study.

Click here for file

[http://www.biomedcentral.com/content/supplementary/17456150-4-10-S1.zip]

\section{References}

I. Lindsay H, Yap VB, Ying H, Huttley GA: Pitfalls of the most commonly used models of context dependent substitution. Biology Direct 2008, 3:52. 